Mongolian Academy of Sciences
Mongolian Journal of Chemistry
The Institute of Chemistry \& Chemical Technology

\title{
Antioxidative activity of Silibum Marianum cultivated in Mongolia
}

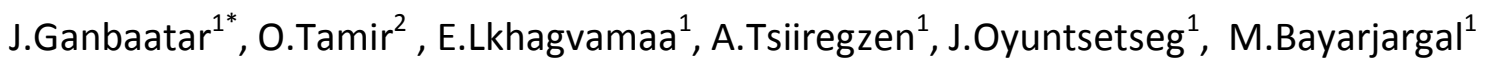 \\ ${ }^{1}$ Institute of Chemistry and Chemical Technology, MAS, Peace ave., Ulaanbaatar,13330, Mongolia \\ ${ }^{2}$ Ereentsav Co.Ltd, Dornod, Mongolia
}

ARTICLE INFO: Received 01 November 2014; revised 14 November 2014; accepted 28 November 2014

\begin{abstract}
Silibum marianum (Milk thistle) contains high amount of phenolic compounds with antioxidant properties. The aim of this work was to evaluate the antioxidant activity of phenolic compounds included in Milk thistle. The antioxidant properties of the leaves and seeds of milk thistle were examined by determining its ability to scavenge the 2,2-diphenyl-1picrylhydrazyl (DPPH) free radical. The results obtained from DPPH assay confirm that Milk thistle extracts have high antioxidative activity.
\end{abstract}

Keywords: silymarin; Silibum marianum; Milk thistle; antioxidant activity

\section{INTRODUCTION}

Silybum marianum (L.) Gaerth (Milk thistle) (Asteraceae family) is a medical plant widely used in a traditional European medicine [1]. The fruit of this plant is used in the form of liquid extracts for treatment of liver and gallbladder disorders, including hepatitis and cirrhosis, and to protect the liver against poisoning from wild mushroom, alcohol, chemical, and environmental toxins. The efficiency of the extracts from the Milk thistle fruit for a treatment of liver diseases actuated their examination in a chemical and pharmacological sense. Nowadays, standardized mixture of flavonoids, known as silymarin or silymarin complex, is used as hepatoprotective pharmaceutical preparations. Silymarin, in the form of standardized liquid or dry extracts, is used like mono- and polycomponent phytopreparations in combination with other medical plants with a similar effect [2].

Silymarin represents a mixture of three isomers: silibinin, silidianin, and silicristin, with a molecular formula $\mathrm{C}_{25} \mathrm{H}_{22} \mathrm{O}_{10}$ and of the molecular weight 482.4 (Figure 1). Silymarin belongs to the class of natural substances with a benzodioxane group in a molecule, which originates in coupling of taxifolin with coniferyl alcohol. Because of this type of the connection within the molecule, this class of compounds was named flavonolignans. Some researchers examined antiinflammatory and anti-allergic activity of silymarin and silibinin [3-4].

This plant species is successfully cultivated in many countries of the world including in Dornod province, Chuluunkhoroot soum, Mongolia, by Ereentsav CoLTd. The aim of this study is to evaluate the

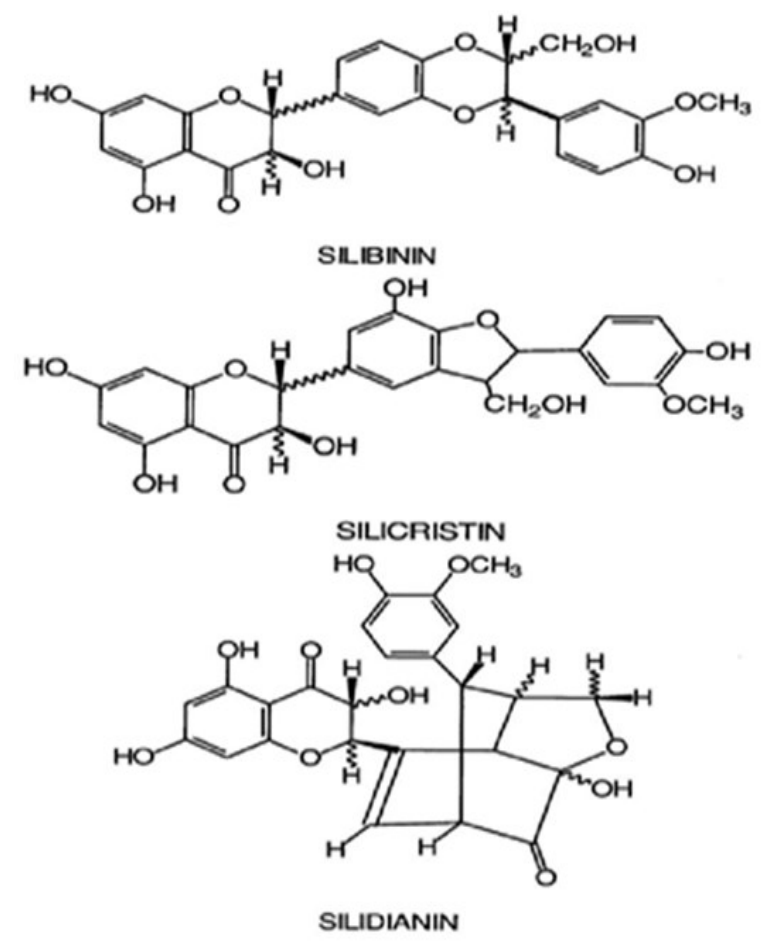

Fig. 1. Chemical structure of the most important ingredients of S. marianum

antioxidative activity of methanolic extracts of the seeds and leaves of $S$. marianum cultivated in Mongolia.

\section{MATERIALS AND METHODS}

Raw Material: Seeds and leaves of Milk thistle, cultivated in Chuluunkhoroot soum of the Dornod

* corresponding author: e-mail: ganbaatar_jamsranjav@yahoo.com

DOI: http://doi.dx.org/10.5564/mjc.v15i0.323 
province (Mongolia) were collected and dried naturally. The voucher specimen was deposited in the herbarium collection of the Institute of Botany, Mongolian Academy of Sciences. After drying, each crude drugs were extracted by methanol and concentrated under reduced pressure. The solvent used for extraction process was in an analytical grade. DPPH (2,2-diphenyl-1-picrylhydrazyl) was purchased from Sigma-Aldrich.

Antioxidant Capacity Measurement: The antioxidantive activity of the extracts was measured in terms of radical scavenging ability using the stable radical 2,2-diphenyl-1-picrylhydrazyl (DPPH) in a spectrophotometric test according to the method described by Sanchez-Moreno [5]. DPPH is a stable highly colored free radical that can abstract labile hydrogen atoms from phenolic antioxidants with concomitant formation of a colorless hydrazine (DPPH -H) [6]. The free radical scavenging activity (FRSA) of an extract can be expressed as the percentage of DPPH reduced by a given amount of extract. In this experiment, $3.9 \mathrm{~mL}$ DPPH solution $(0.0125 \mathrm{~g}$ in $500 \mathrm{~mL}$ methanol) was taken to mix with $0.1 \mathrm{~mL}$ seeds or leaves methanol extracts then the mixture was left in the dark at room temperature for $40 \mathrm{~min}$. The control included only methanol $(0.1 \mathrm{~mL})$ and DPPH solution. The absorbance was measured at $517 \mathrm{~nm}$ against methanol as the blank. The total FRSA of each extract was expressed as the percentage of DPPH reduced and was calculated by the following equation:

DPPH scavenging activity, $\%=\frac{\text { Absorbance }_{\text {control }}-\text { Absorbance }_{\text {sample }}}{\text { Absorbance }_{\text {control }}} \times 100$

Where:

$\mathrm{A}_{\text {control }}$ is the absorbance of only DPPH solution and

$A_{\text {sample }}$ is the absorbance of sample at $517 \mathrm{~nm}$ wavelength

\section{RESULTS AND DISCUSSION}

Seeds and leaves of Milk thistle usually used in medical practice. Antioxidant properties of seeds and leaves extracts were evaluated by determining their

Table 1. The IC $\mathrm{C}_{50}$ of the leaves and seeds of S. marianum

\begin{tabular}{|c|c|c|}
\hline $\begin{array}{c}\text { Sample, } \\
\mu \mathrm{g} / \mathrm{ml}\end{array}$ & $\begin{array}{c}\text { DPPH } \\
\text { scavenging } \\
\text { activity, } \\
\%\end{array}$ & $\begin{array}{l}\mathrm{IC}_{50} \text { (sample concentration } \\
\text { required to scavenging } 50 \% \\
\text { of the DPPH radicals), } \mu \mathrm{g} / \mathrm{ml}\end{array}$ \\
\hline \multicolumn{3}{|c|}{ Leaves } \\
\hline 1600 & 43.7 & \multirow{4}{*}{1800} \\
\hline 800 & 21.2 & \\
\hline 400 & 9.8 & \\
\hline 200 & 5.5 & \\
\hline \multicolumn{3}{|c|}{ Seeds } \\
\hline 800 & 86.4 & \multirow{4}{*}{268} \\
\hline 400 & 71.2 & \\
\hline 200 & 40.7 & \\
\hline 100 & 23.2 & \\
\hline
\end{tabular}
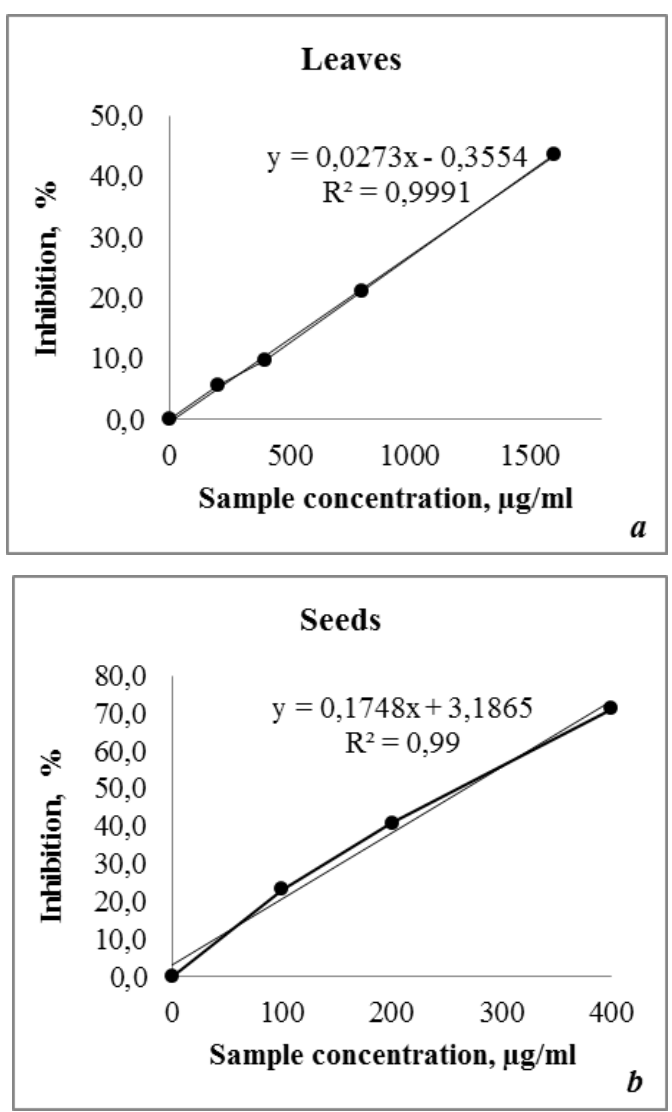

Fig. 2. Linear regration of the leaves (a) and seeds (b) of the methanolic extracts of $S$. marianum

ability to scavenge the DPPH free radical. DPPH scavenging activity was expressed as an $\mathrm{IC}_{50}$ (sample concentration required to scavenging $50 \%$ of the DPPH radicals) in $\mu \mathrm{g} / \mathrm{ml}$. In figure 2 shown the linear regration of the leaves (a) and seeds (b) methanolic extracts of $S$. marianum.

Seeds and leaves methanolic extracts of Milk thistle, cultivated in Mongolia exhibited high antioxidative activity that was identical to the research results of other scientists (table 1) [7].

The $I C_{50}$ of the leaves of Milk thistle was higher $(1800 \mu \mathrm{g} / \mathrm{ml})$ than seeds $(268 \mu \mathrm{g} / \mathrm{ml})$. It means that the antioxidative activity of the seeds higher than leaves.

\section{CONCLUSION}

The results obtained from the DPPH assay confirm that Milk thistle extracts have high antioxidative activity. The $\mathrm{IC}_{50}$ of leaves of Milk thistle was higher $(1800 \mu \mathrm{g} / \mathrm{ml})$ than seeds $(268 \mu \mathrm{g} / \mathrm{ml})$. The antioxidant activity of the seeds prevails activity of leaves more than 6 times.

\section{REFERENCES}

1. Morazzoni P., Bombardelli E. (1995). Application of Silybum marianum (Carduus marianus). Fitoterapia, 66(1) 3-42.

2. Rote Lste., Service Gmg H., Frankfurt/Main. (1966). Arzneimittelverzeichnis des 
Bundesverbandes der Pharmazeutischen Industrie, ECV-Editio Cantor, Aulendorf/Wurtt

3. Manna S.K., Mukhopadhyay A., Van N.T., Aggarwal B.B. (1999). Silymarin suppresses TNFinduced activation of NF-k B, c-Jun N-terminal kinase, and apoptosis, Journal of Immunology, 163 (12) 6800-6809.

4. Havsteen B. (1983). Flavonoids, a class of natural products of high pharmacological potency. Biochemical Pharmacology, 32(7) 1141-1148.

5. Sanchez-Moreno C., Larrauri J.A., Saura-Calixto F. (1998). A procedure to measure the antiradical efficiency of polyphenols. J. Agric. Food Chem., 76 (2), 270-276.
6. Diouf P.N., Stevanovic T., Cloutier A. (2009). Antioxidant properties and polyphenol contents of trembling Aspen Bark extracts. Wood Sci. Technol. , 43 (5-6), 457-470.

7. Ece Z., Seher K., Sezin G., Sebnem T. (2011) Ultrasound-assisted extraction of Silymarin components from milk thistle seeds (Silybum marianum L). GIDA, 36(6), 311-318 